\section{Technological and Technical Issues of Efficient Nutrient Supply}

\author{
Attila Kőkuti \\ Tornádó International Ltd., Szeged \\ dr_kokuti_attila@tornado-international.hu
}

\section{SUMMARY}

Efficient plant production requires modern production technologies, including a nutrient supply of a scientific basis. The harmonic nutrient supply of quality products that are required by market demands can be produced by the optimal combination of a compound system of requirements. These requirements are partly preparatory (soil investigations, yield measurements, preparation of digital field maps) and are partly based on the knowledge of the most significant characteristics of the applied nutrients. Most artificial fertilizers are applied by spinning disc fertilizer spreaders all over the world, therefore, it is advisable to use them in Hungary as well. Importantly, these machines should be well adjustable, capable of the exact measurement and control of the spread quantity, as well as of even spreading. My report has investigated only the most significant technical requirements affecting the even application of nutrients.

Keywords: spinning disc fertilizer spreaders, site specific nutrient application, physical properties of fertilizers, calibration of spreaders, spreading on the edges of fields, spreading pattern, spreading unevenness (CV\%), tramline system, parallel moving

\section{INTRODUCTION}

Efficient plant production requires modern production technologies, including a scientifically calculated nutrient supply. The harmonious nutrient supply of quality products that are required by market demands can be produced by the optimal combination of a system of requirements. These requirements are partly preparatory (soil investigations, yield measurements, preparation of digital field maps) partly based on the knowledge of the most significant characteristics of the applied nutrients (manure and artificial fertilizers) (Neményi et al., 2002a, 2002b; Németh, 2000), and they are also of a technical nature. In Hungary artificial fertilizers dominate in nutrient supply, as manure producing capacities $(0.5 \mathrm{animal} / \mathrm{ha})$ can cover only one fifth of the whole nutrient demand and with the increase of nutrient levels, even smaller percentage of it.

Naturally, the rational use of manure, compost and by-products is highly important. Artificial fertilizers are applied by spinning disc fertilizer spreaders all over the world, therefore, it is advisable to use them in Hungary as well. Importantly, these machines should be well adjustable, capable of the exact measurement and control of the spread quantity, and ensure even spreading. My report has investigated only the most significant technical requirements affecting the even application of nutrients. The following items are decisive:

- the construction of machines;
- the understanding of parameters required for the calibration of machines;

- the professional calibration and operation of machines, including the exact compliance with the required working width, which can be performed in several ways:

o with a path for cultivation

0 with a foam marker for boomed machines

o with an apparatus providing parallel movement

- the maintenance of machines;

- the taking of environmental viewpoints into consideration.

With production site-specific nutrient supply, which allows for the above mentioned items, environmentally friendly farming and products of verified quality can be provided (Fekete, 2000; Mesterházi et al., 2003; Pecze, 2001). All the above requirements are of equal significance, and the lack of them can have a negative impact on farmers' objectives.

\section{ISSUES OF CONSTRUCTION IN THE CASE OF FERTILIZER SPREADERS}

The various types of construction for spinning disc fertilizer spreaders largely define the working quality and the value of use. Therefore, when evaluating these machines, the following should be taken into consideration:

- the hopper should have a mesh size with a loading screen of not more than $20 \mathrm{~mm}$;

- the volume of the hopper (in the case of suspended apparatuses) should consider the stability and lifting capacity of the power machine (the volume of the hopper) should be variable with adjustable parts;

- the volume of the hopper (in the case of boomed equipment) should be harmonized with the parameters of the wheels;

- the angle of the tank's side should be adjusted to the angle of repose of fertilizers;

- above the throat (in the case of gravitational dosage) there should be a device of slow rotation per minute (rpm) or a small number of oscillations to prevent vaulting $(n=100-150$ $1 / \mathrm{min}$ ). A faster device that prevents vaulting would break fertilizer particles into small pieces, thus it would reduce the preferred working width and would impair the quality of work;

- a correct calibration table to set the volume of doses is significant, which provides the identification of the most essential characteristics of fertilizers to be applied and which contains the parameters necessary for calibration; 
- advantageously, the slot of dosage can be adjusted, as the optimal working quality that can be obtained by fertilizers of varying physical properties can be best achieved in this way;

- clear instructions should be presented on the calibration of spinning discs (revolutions per minute, direction of rotation, height above the soil, angle included with the horizontal line, calibration of blades) in the machines' manuals and calibration tables (Csizmazia and Polyák, 1997a, 1997b);

- the calibration table should contain the precise description of the essential calibration providing the required working width with various fertilizers;

- opportunities for precise spreading on the edges of fields, sides of the ditches and the sides of roads should be provided, as these are essential from the viewpoints of cost efficiency and environmental protection.

The above characteristics should be considered as they are essential for the effective application of nutrients, preventing environmental damages.

\section{CALIBRATION OF FERTILIZER SPREADERS}

High precision that can be tailored to local conditions and requirements within a production site can be realized through exact measurements and precisely regulated interventions. The careful calibration of machines is the prerequisite for exact measurement and precisely regulated interventions. In the case of a machine calibrated according to the table of dosage, a trial operation should always be carried out, as the characteristics of the actually used fertilizers are not necessarily the same as the characteristics of fertilizers applied in the course of preparing the table of dosage. Modern machines are usually equipped with a set of tools for testing the volume of dosage (if it is an optional tool, its purchase is recommended).Trial operations should always take place when the machines work under circumstances similar to those in the fields, as only in this way can we expect realistic results.

In case of the given fertilizer, the expectable working width of machines can only be identified by professional examinations. We should not purchase and operate a machine that does not have a calibration table based on such findings. Even in the case of a machine calibrated on the basis of the proper calibration table, it is advisable to check the working quality of the machine as it is mentioned above; the physical characteristics of fertilizers differ from that of the ones applied in the preparation of the table of dosage. Trading companies supply sets of tools for field tests either as basic equipment or as an optional item, and their application prevents the accidental mistakes of calibration.

\section{PROFESSIONAL OPERATION OF MACHINES}

Good construction and optimal calibration do not guarantee good working quality, as all the can be easily spoilt by inappropriate operation. It is wellknown and observable that in the course of moving away from the middle line of machines, differing quantities of fertilizers are applied in the so-called transversal spreading pattern of spinning disc spreaders (perpendicular to the direction of moving). The nature of transversal spreading pattern is the matter of construction and calibration. The two common sub-types are trapezium and triangle spreading patterns. Independently of the types, the machine has to be operated with an overlapping to achieve even fertilizer distribution. The range of overlapping and the unevenness of transversal spreading can only be identified on a test track. If the range of overlapping is only eyeballed, gross errors can result. We can state that deviations from the optimal working width are primarily responsible for the mistakes in the working quality of spinning disc spreaders.

It is commonly known that the rate of spreading unevenness $(\mathrm{CV} \%)$ can affect both production yields (Figure 1) and the quality of products.

Figure 1: Relations of spreading unevenness and reductions in production yields

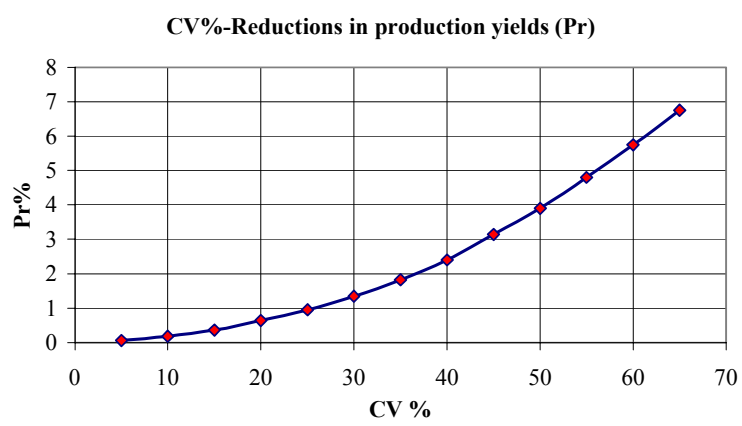

For favourable fertilizer distribution, it is essential to keep the working width that is the prerequisite of optimal spreading unevenness. It also means that appropriate equipment should be used to keep the planned and calibrated working width within the site of cultivation.

Production using tramline system has created opportunities for keeping the appropriate working width. The prerequisite of the selected cultivation path is the precise calibration of the working width of machines.

Earlier, when there were no tramline system, only foam markers were available, which could only be applied in the case of machines with booms (e.g. pneumatic machines), as machines were not equipped with supplementary booms constructed especially for this reason. Moreover, the preciseness of adjustment available by the above mentioned foam markers resulted in deviations of several meters, which, in the case of a trapezium-shaped spreading pattern caused greater deviations than the acceptable ones. It also caused a considerable increase of unevenness in the case of triangle-shaped spreading patterns as well. With a sound knowledge of all these, the development of equipment that provides parallel moving (Figure 2) has been of primary importance, 
as these GPS supported systems allow the connecting preciseness of $15-20 \mathrm{~cm}$, which is acceptable taking the nature of transversal spreading patterns into consideration. The equipment for parallel movement, having been adjusted to the two points of reference, ensures parallel moving according to the previously calibrated working width. The device can also be used in darkness and in foggy weather conditions, as a row of lights indicates the deviance from the optimal direction for the tractor driver, facilitating the easy correction of the mistake.

Figure 2: Parts of the equipment for parallel moving

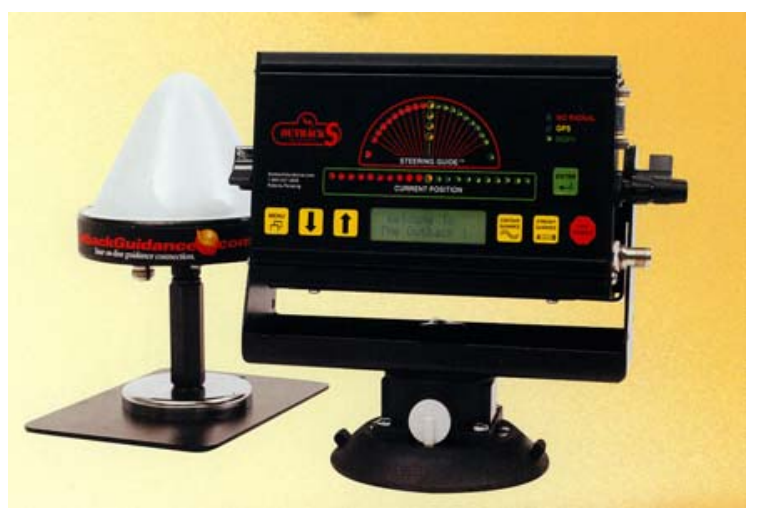

We can generally say that a deviation which is smaller than $1 \mathrm{~m}$ and takes place in the course of changes in the range of the values of overlapping, in the case of a favourable spreading pattern, does not usually alter transversal spreading unevenness more than allowed in the acceptable domain (Figure 3).

Figure 3: Transversal spreading pattern and spreading unevenness changing with the values of overlapping

Spreading pattern

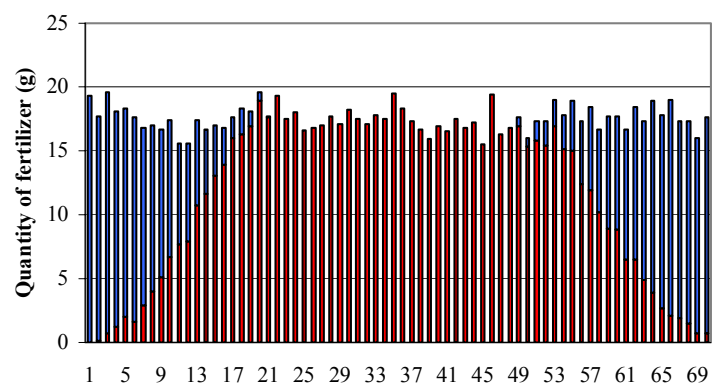

Measuring trays

CV \%-Working width

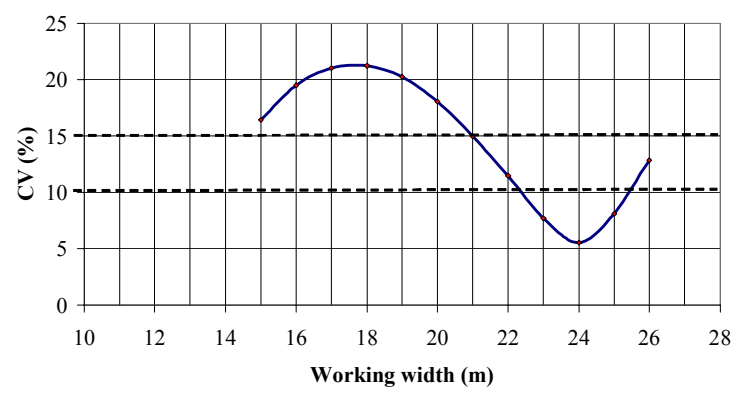

Figure 3 shows that the value of spreading unevenness is below $\sim 5 \%$ with a working width of 24 $\mathrm{m}$. In the case of a deviation of $\pm 1 \mathrm{~m}$ the value of spreading unevenness remains under $8 \%$. In spreading patterns of trapezium shapes, the range of overlapping exerts a greater influence on the values of spreading unevenness. Cultivation methods with tramline system and the equipment for parallel moving keep the values of transversal spreading unevenness within the acceptable domain even in this case.

\section{MAINTENANCE OF FERTILIZER SPREADERS}

The issues of maintenance for fertilizer spreaders is worth a special consideration, as significant practical mistakes occur relatedly. Emphasis should be placed on the fact that the quality of work attainable by spinning disc fertilizer spreaders is considerably impaired, if the parameters of the machines deviate from those calibrated in factories. Deviation may originate in the deformation of machines as a result of inappropriate filling (e.g. drastic reverse gear). The deformation of spinning discs can significantly affect the working quality of machines, which may originate in drastic injuries or the attrition of bearings. Further problems may come from the attrition or injuries of spreading blades, or the application of not the original spreading blades, which can impair the working quality of the machines significantly. According to general practice, spreading blades are used as long as their surfaces get rough, or get punctured. Comparative studies with new and attrited blades show (Ancza, 2003) that attrited blades result in the considerable reduction of working quality. These investigations were performed with reliable fertilizer spreaders, under strict calibration. Comparison was carried out on the basis of three indicators identified by standards: the indicator of medium deviation (acceptable value: $10 \%$ ), the indicator of the greatest deviation (acceptable value: $20 \%$ ) and the indicator of the coefficient of variation (CV) (acceptable value: $15 \%)$. The value of medium deviation with new blades is $7.7 \%$, with attrited blades it is $18.19 \%$. The greatest deviation is $18.08 \%$ with new blades, with attrited blades it is $46.97 \%$. The value of the coefficient of variation is $9.43 \%$ with new blades, and it is $22.23 \%$ with attrited ones. Therefore, it can be concluded that the extreme attrition of blades significantly impaired transversal spreading patterns and thus the quality parameters of spreading. The machines could not fulfill any of the standard requirements with attrited blades. If we consider the fact that the value of spreading unevenness which is more than $20 \%$ results in about $1 \%$ yield reduction in itself, we can clearly see the significance of changing the attrited blades in good time. We have often experienced that attrited and unusable blades are sometimes changed for home-made blades. It is needless to state that the application of injured or home-made blades results in problems whose costs are considerably higher than the original price of new blades. 


\section{SITE SPECIFIC NUTRIENT APPLICATION}

Site specific, environmentally harmless fertilization, applied with a proper background knowledge of the findings of investigations tailored to plants' nutrient demands on a given production site, reduces the quantity of applied fertilizers and seeds. It can also increase specific production yields by up to $11-16 \%$ and can also improve the quality of crops (Fekete, 2000). However, all these can only be applied on the desirable level, if the above mentioned requirements of technology and operation are fulfilled. If not, the achievement of the expected results does not seem to be realistic. This fact must be highlighted, as we can easily think that the application of the achievements of modern technology (e.g. GPS) is omnipotent, whereas it is only efficient if all the requirements are optimally and concurrently fulfilled. Therefore, it is significant to consider the issue of modern nutrient management

Figure 4: Quantity regulation during operation

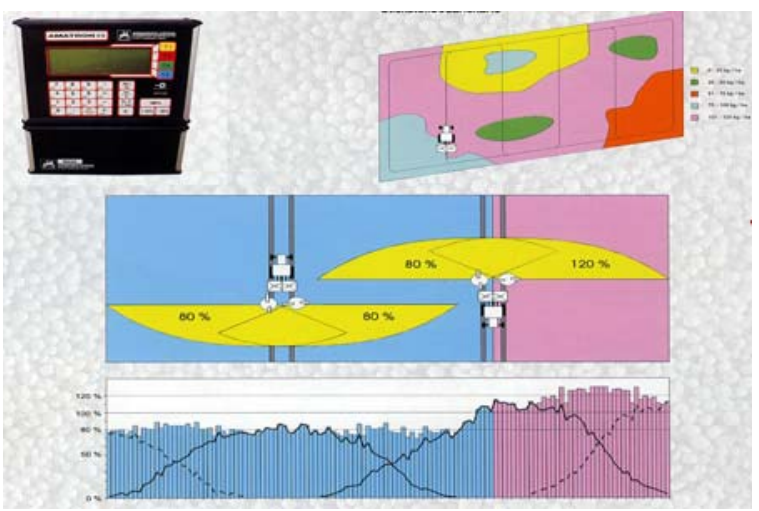

Figure 5 shows (upside down): normal spreading (the rpm of the left and right discs are the same), wedge-type spreading (the rpm of the two spinning discs slightly differ), edge-type spreading (the rpm of the left disc is considerably reduced) and boundarytype spreading (where the rpm of the left disc is scarcely higher than that of the right disc). The rational calibration of the rpm of the left and right discs can provide the above mentioned special spreading patterns. Wedge-type spreading has become a constantly emerging need in the management of irregularly shaped production sites, in its complexity and not to simplify it to certain technological problems. If all the above listed requirements are optimally fulfilled, we can safely expect that we can achieve the target yields of target quality.

Fertilizer spreaders which are equipped with GPS offer other services as well and they react more and more precisely to the changes demanded by digital field maps. They can usually guarantee the variation of two parameters, the asymmetric variation of the throat belonging to the two spinning discs, and the variation of the rpm (rotations per minute) of the spinning discs related to each other. With these two variations and their combination both differentiated fertilizer application (Figure 4) and various spreading patterns can be realized (Figure 5).

Doses of nitrogen fertilizers in the order of $\mathrm{kg} / \mathrm{ha}$ on Figure 4: 0-25 (yellow), 26-50 (green), 51-75 (red), 76-100 (grey), 101-125 (pink).

Figure 5: Various forms of spreading
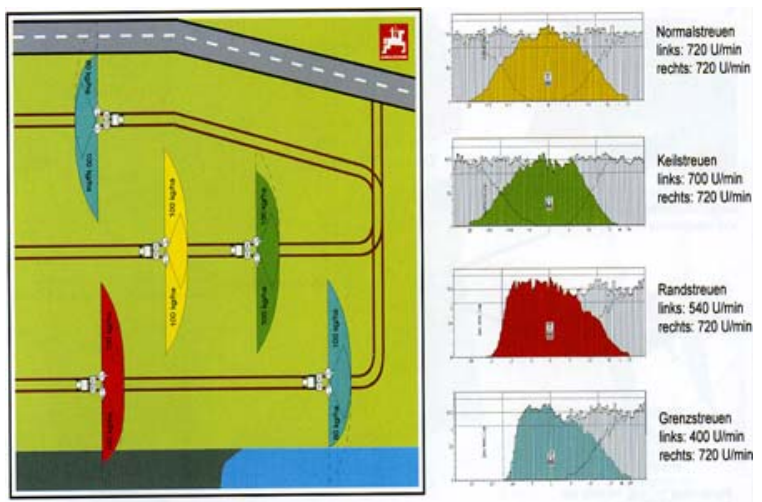

edge-type spreading is required in the vicinity of streams and roads, whereas boundary-type spreading means that spreading is carried out next to other production sites.

In conclusion we can state that nutrient management, which is suitable for the production of quality products, can be achieved as a result of the optimal fulfillment of various requirements. If any of these requirements are not satisfied, the result can impair the impact of the others, so all the above mentioned issues need thorough consideration.

\section{REFERENCES}

Ancza, E. (2003): Characteristics and Impacts of the Spreading Blades of Spinning Disc Spreaders. Conference on Research and Development, Gödöllő

Csizmazia, Z.-Polyák, N. I. (1997a): Design and Control Questions of Rotary Disc Fertilizer Spreader Machines. Hungarian Agricultural Engineering, 10. 22-24.

Csizmazia, Z.-Polyák, N. I. (1997b): Issues of Construction and Regulation with Spinning Disc Fertilizer Spreaders. Mezögazdasági Technika, 38. 5. 2-4.

Fekete, A. (2000): Precision Production. Agrofórum, 14. 11. 5455.

Mesterházi, P. Á.-Neményi, M.-Kovács, A.-Kacz, K.-Stépán, Zs. (2003): Development of Site-Specific Nutrient Replacement. $14^{\text {th }}$ International Symposium of Fertilizers (CIEC), Fertilizers in Context with Resource Management in Agriculture,
Proceedings, 1. 288-295.

Neményi, M.-Mesterházi, P. Á.-Pecze, Zs.-Stépán, Zs. (2002): The Role of GIS and GPS in Precision Farming. Computers and Electronics in Agriculture, 40. 1-3. 45-55. If.: 0,39.

Neményi， M.-Pecze，Zs.-Mesterházi， P. Á.-Kiss， E. (2002). Engineering Environment of Precision Crop Production. Hungarian Agricultural Engineering, 15. 89-91.

Németh, T. (2000): Ideas about Nutrient Management at the Beginning of the XXI ${ }^{\text {th }}$ Century. Agrofórum, 11. 14. 26-28.

Pecze, Zs.-Neményi, M.-Mesterházi, P. Á.-Stépán, Zs. (2001): The Function of the Geographic Information System (GIS) in Precision Farming. IFAC/CIGR Fourth International Workshop on Artificial Intelligence in Agriculture (Preprints edited by Prof. Farkas, I.)

Publications of AMAZONE and TRIMBLE (firms) 